\title{
Research on the Development of "Double Abilities" of English Majors through Project-based Assignment Based on Constructivist Learning Theory
}

\author{
Min Sun ${ }^{a}$, Yanchun Qiu ${ }^{b}$ \\ Qingdao Binhai University, Foreign Language Institute, Qingdao, Shandong, 266555 \\ E-mail: a2674597727@qq.com, b975581248@qq.com
}

Keywords: Project-based Assignment, Translation Practice Development of the Critical Thinking and Creative Abilities

\begin{abstract}
A study of translation theory was put on the top of priority in the traditional translation teaching, while translation practice was often ignored. As a result, English majors lacked initiative and creativity, even worse, the evaluation system "Final exam is everything" drove students to ignore the process of learning and practice. Given that, the mode "project-based assignment" is put into practice in the translation teaching class to help students learn translation theory and make translation practice as well. In this case, students pay more attention to translating process; therefore, their critical thinking and creative abilities, which are the prerequisite in improving their translation competence, can be developed and their esprit de corps can be created more easily by cooperating with others.
\end{abstract}

\section{Introduction}

In traditional college English translation class, the teaching method - "theory teaching - student practice - checking the standard answers", had many drawbacks. First, it was easy to form "the "only teacher's voice" atmosphere in class, and the dull and boring translation theory often made students sleepy, which turned out to be low teaching efficiency. Second, as students had less practice, it is difficult for them to apply translation theory to instruct their translation practice. Third, students were used to depending on "standard answers", therefore, their thinking and innovative abilities could not be improved appropriately.

With the development of society, the teaching mode of "theory teaching-student practice-checking the standard answers" adopted in the traditional translation class with teachers as the main body and leading role was not adapt to the Post-90s college students, for the capabilites of the students taught in this teaching mode cannot be matched with the requirements in the changing world. Therefore, it is a must for universities to have a reform in college English translation class.

\section{Analysis of the Status Quo of Students' English Translation Studies}

In the teaching practice in recent years, the author has found that college English majors lack general awareness of innovation.

Influenced by traditional education, obviously, quite a few students have depending psychology and blind obedience, and lack questioning and critical spirit.They dare not question or challenge the authorities, even worse, they are not willing to have in-dept study of their courses and never have their own opinions in or after class. Some students are forced to learn knowledge just for getting a diploma or find a job. Since they are not willing to think independently in their study, they lack the awareness of innovation, and dare not have any creation or innovation.

The inherent perseverance of innovation is insufficient. Innovative consciousness is one of the qualities that everyone in modern society should possess. College students nowadays should have the inherent perseverance of innovation, be brave in innovation, and work hard. However, innovation is very difficult, even efforts may not lead to success, therefore, some students lack the intrinsic motivation and perseverance in innovation. As soon as they encounter setbacks, they may 
give up immediately.

The innovative practice consciousness is weak. Some students have a certain sense of innovation, but not strong. They seldom practice or are not willing to practice. Some students are lazy in their actual actions, and do not want to carry out translation practice but dream of taking shortcuts. They rely heavily on "standard answers", and never do research possitively and initiatively, even dare not to be creative to find a new way to solve the problems they meet. Since they do not have a strong awareness of practice, and lack creative practice, they cannnot turn the scientific knowledge learned into the internal scientific wisdom. As the result, it is impossible for them to become a real creator but only a storage of knowledge.

As is known to all that critical thinking ability and creative ability are the basic requirements for contemporary college students. In view of this, it is the main task for universities to cultivate students' critical thinking ability and innovative bility.

\section{The Implementation of Project-based Assignment Based on Constructivist Learning Theory}

Constructivism believes that one cannot get knowledge through teaching, and he or she can only get knowledge in a way of meaning construction with the help of other people (including teachers and learning partners) in the process of acquiring knowledge in a certain context (social and cultural background) and by using some necessary learning tools. Since learning is a process of meaning construction in a certain context, that is, in a social and cultural context, and it can be accomplished with the help of others through interpersonal collaboration activities, the Study Theory of Constructivism holds that context, cooperation, conversation and meaning construction are four important factors of learning. "Situation": The situation in the learning environment must be conducive to the student's meaning construction of what he or she is learning. It puts forward new requirements for instructional design. That is to say, in the constructivist learning environment, not only the analysis of teaching objectives, but also the situation of question-setting that are conducive to students' construction meaning should be taken into consideration in a teaching plan, which is one of the most important part in the teaching plan.

"Collaboration": Collaboration exists throughout the whole learning process. Collaboration plays an important role in the collection and analysis of learning materials, the presentation and verification of hypotheses, the evaluation of learning outcomes, and the final construction of meaning. "Conversation" : refers to how the learning group members discuss with each other to complete the prescribed learning tasks; in addition, the collaborative learning process is also a "discussing " process in which each learner may share others' thinking (wisdom) in the group, thus "discussing" is also one of the important means to achieve meaning construction.

"Meaning construction": This is the ultimate goal in the entire learning process, which refers to understanding the nature, laws and intrinsic connections between things. Helping students to construct meaning in the learning process is to help them to have a deeper understanding of the nature and laws of the things that reflect the internal relationship between the things they have learned and other things. The long-term storage form of this understanding in the brain is the aforementioned "schema", which is the cognitive structure of what is currently being learned. It can be seen from the meaning of "learning" mentioned above that the quality of learning is a function of the learner's ability to construct meaning, rather than a function of the learner to reproduce the ability of the teacher's thinking process. In other words, the amount of knowledge acquired depends on the learner's ability to construct the meaning of the knowledge based on his or her own experience, not on the learner's memory and the ability to recite what his or her teachers have taught. $^{[1]}$

Constructivism believes that teachers are helpers and facilitators of meaning construction, not knowledge givers and indoctrinators. Students are the principal parts in information processing, for they are the active constructor of meaning, not the passive recipient of external stimuli and the instilled objects. They should become the active constructors of meaning who: (1) construct the meaning of knowledge through exploration and discovery; (2) in the process of constructing 
meaning, take the initiative to collect and analyze relevant information and materials to the problems they meet in study, and make various assumptions and try to verify them; (3) try to find the internal relations between the things they are learning and the things they have learned. ${ }^{[2]}$

Constructivism requires that some common problems should be discussed and explored among teachers and their students, or among students themselves so that they may learn more from others by exchanging ideas and questioning.

It is emphasized in the "Teaching Standards" from the Ministry of Education that English teaching should be based on constructivism. It stipulates that open-ended task-based activities and exploratory learning content should be added in classroom teaching, and the supporting "extra-curricular project-based" model is proposed. ${ }^{[3]}$ The project-based assignment should be done by the cooperation of students.Through collaboration, students collect and analyze learning materials, make assumptions and verify them, and complete the final construction of the knowledge system through self-feedback in the learning process and evaluation of learning results. "Task implementations in class, project-based assignment, and procedural evaluation "are the respects of the whole teaching. The research and reform on homework assignment will help solve the problems arising in task-based teaching, and better and fill vitality to it.

Based on the constructivist learning theory and the requirement of "the Standard of Translation Class Teaching” by the Ministry of Education, the mode of project-based assignment is introduced to translation teaching class. "Project"means adopting a number of communicative and learning activities to solve a problem in language use. Teachers should design some operable projecte-oriented tasks focusing on specific communicative purposes and language practice for the students, and the students are requested to write down the process of completing projects in groups on the basis of cooperation, and other activities and evaluate each other, and then demonstrate their works in class.

The implementation of "project-based assignment" may enable students to review and consolidate their knowledge, change mechanical learning into a meaningfully possitive learning, and arouse their interest and improving their ability of independent study, such as learning to cooperate with others, making decisions, collecting information, and solving problems, and enhance their all-round development.

The project-based assignment is an extension of classroom teaching. It is also an important means of improving students' abilities of information collection, retrieval, classification, analysis and application. However, the amount of the project-based assignment cannot be beyond the students' knowledge and ability. If it is too little, students' translation competence may not be enhanced; if it is too much, the students may fail to finish doing all. As the result, it will seriously dampen the students' enthusiasm in learning. Therefore, the design of project-based assignment should not be underestimated. In the process of translation teaching, the author selects four items in one semester: translation of public signs, translation of advertisement, translation of tourist materials, and translation of news headlines. Each project is required to complete within a month. After being completed, the representatives of each group should demonstrate their works in the form of PPT in class, and other groups will point out the problems in their works. After that, each group has to corret the mistakes in their translation works and then hand in their corrected assignment. The teacher gives the final evaluation (marks) by group.

The public signs can be seen everwhere in our life, thus, it is easy for students to collect. After their collection, they should classify them, and then do translation according to the basic translation principles and the functions of the public signs (indication, prompt, warning and coerciveness), and then fill in the the corresponding task report.

Nowadays advertisement has filled very corner of our life, and we can say that it is aur fingertips. Therefore, there is no difficulty in getting advertising materials as translation practice materials. After their collection, the students also have to classify them first and then do translation practice according to the translation principles and the language features of advertisement.

The translation of the tourism materials is aimed to help students learn more about Chinese and foreign tourist attractions and arouse their love of nature. For English-Chinese translation of tourism 
materials, students are required to go online to find some original English materials of tourist destinations around the world. The purpose is to let students know the English expressions of tourism materials. The students are required to traslate the materials first by themselves, and then try to find some excellent versions to have comparision to find the differences between English and Chinese in describing or introducing the scenic spots ( In English, "realistic description" is focused on, therefore, the language is simple in description without many rhetorical words, while in Chinese, freehand description can be read frequently with gorgrous words). If the students understand these differences, they may do their translation of tourism materials flexibly.

The translation of the news headlines is aimed to encourage students to learn more about main events both at home and abroad, and inspire them to concern themselves with state affairs and have a world vision. Each student is required to find 10 items of news headlines for translation, and then have a discussion in their own group. After that they must make an analysis of their translation under the guidance of the translation theory they have learned.

"Translation competence cannot be obtained by teaching but only by practice." ${ }^{\text {[4] }}$ Through the implementation of project-based assignment, in the process of discussing with other groupmates, the students constantly correct their ideas, rethink and combine the translation methods and techniques they have learned so that at last they may form new translation results. If the students find that their inferences are correct in the group discussion, their self-confidence will be enhanced and the enthusiasm for learning will be triggered. In this way, after thinking, observing, discovering, and discussing, the students acquire the ability to do translation properly in the appropriate occasions, complete the active construction process of knowledge, and achieve a good meaning construction. ${ }^{[5]}$

Seen from the questionnaire below, the implementation of the project-based assignment has not only improved the students' translation competence, but also has a great effect on the students' critical thinking ability and innovation ability.

\section{The Impact of Project-based Assignment on Students' Critical Thinking Ability and Innovative Ability}

Critical thinking ability means the ability of thinking and analysis. The so-called thinking refers to thinking activities such as analysis, reasoning, and judgment; the so-called discrimination refers to the discrimination and analysis of the situation, category, and reasons. During the course of the implementation of project-based assignment, first, the students should collect relevant translation materials, then classify them and do translation practice with the help of network or other learning tools. Besides, they must learn how to analyze the advantages and disadvantages of their own translated works. If they can find out their own deficiencies and problems through analysis, their critical thinking ability is sure to be improved. Specifically, the design of the project-based assignment mainly includes the following aspects: the purpose and significance of the project implementation, the project implementation content and key issues to be solved, the project implementation plan and the methods to solve the problems, arrangement of operation of the project process, the summary, translation practice and evaluation. In the process of completing the project, the students' innovative thinking ability is also trained. For example, by writing a report of a project-based assigment, the students understand the purpose and significance of the implementation of it, clarify the goals, and know what problems to solve, thus, they can propose some corresponding solutions to the problems, and make specific decisions on the project process according to the task. Finally, They must make a summary about the whole task to find out their achievements and deficiencies. This kind of training can strengthen students' logical thinking ability and writing competence. In the process of translation practice, students can express their own opinions and ideas, put forard skeptical and reasonable "critical" views on the existing translated text instead of blind obedience, convince, satisfaction with only one translated version, and very often they would like to provide several versions. Sometimes, the students may discover certain rules, and create similar translations by imitating the other's version to improve their divergent thinking. Judging from the works translated by the students, we can see that some students are able 
to get rid of the negative transfer effect of the original text in the process of translation, and flexibly deal with the language and cultural vacancies in the process of bilingual conversion.

All in all, from the learning results and feedback of students, the implementation of project-based assignment has greatly inspired the enthusiasm of students to learning translation and do some research possitively, improved the effectiveness of classroom teaching and the actual translation level of students. The following questionnaire data on project-based assignment comes from three different grades:

\begin{tabular}{|c|c|c|c|c|c|c|c|}
\hline & Grade & \multicolumn{2}{|c|}{2013} & \multicolumn{2}{|c|}{2014} & \multicolumn{2}{|c|}{2015} \\
\hline questions & options & $\begin{array}{l}\text { Number of } \\
\text { participants }\end{array}$ & Percentage & $\begin{array}{l}\text { Number of } \\
\text { participants }\end{array}$ & Percentage & $\begin{array}{l}\text { Number of } \\
\text { participants }\end{array}$ & Percentage \\
\hline \multirow{3}{*}{$\begin{array}{l}\text { 1. Your } \\
\text { translation } \\
\text { competence } \\
\text { has been } \\
\text { improved by } \\
\text { doing the } \\
\text { project-based } \\
\text { assignment }\end{array}$} & $\begin{array}{c}\text { A.improved } \\
\text { a lot }\end{array}$ & 4 & $3.9 \%$ & 3 & $3.9 \%$ & 11 & $11.828 \%$ \\
\hline & $\begin{array}{c}\text { B.improved } \\
\text { a little }\end{array}$ & 44 & $56.6 \%$ & 43 & $56.6 \%$ & 62 & $67.742 \%$ \\
\hline & $\begin{array}{c}\text { C.not } \\
\text { improved at } \\
\text { all }\end{array}$ & 19 & $39.5 \%$ & 30 & $39.5 \%$ & 19 & $20.43 \%$ \\
\hline \multirow{4}{*}{$\begin{array}{l}\text { 2. Your } \\
\text { critical } \\
\text { thinking has } \\
\text { been enhanced } \\
\text { by doing the } \\
\text { project-based } \\
\text { assignment }\end{array}$} & $\begin{array}{c}\text { A.trained } \\
\text { well }\end{array}$ & 6 & $9 \%$ & 15 & $19.7 \%$ & 22 & $23.656 \%$ \\
\hline & $\begin{array}{c}\text { B.trained in } \\
\text { some } \\
\text { degree }\end{array}$ & 49 & $73.1 \%$ & 39 & $51.3 \%$ & 60 & $65.591 \%$ \\
\hline & $\begin{array}{l}\text { C. trained } \\
\text { but not } \\
\text { obviously }\end{array}$ & 11 & $16.4 \%$ & 18 & $23.7 \%$ & 8 & $8.602 \%$ \\
\hline & $\begin{array}{l}\text { D.not } \\
\text { trained at } \\
\text { all }\end{array}$ & 1 & $1.5 \%$ & 4 & $5.3 \%$ & 2 & $2.151 \%$ \\
\hline
\end{tabular}

From the table, it can be seen from the result of the questionnaire survey of the same questions by the students of different grades that more than $60 \%$ of the students think that their translation ability has been really improved through the project-based assignment training. It is proved that proper project-based assignment has a significant effect on the improvement of students' actual translation ability and critical thinking ability.

However, any kind of teaching method can't be perfect, just as “ No medicine can cure all diseases”. Due to the differences in individual student habits and learning habits, there are still certain problems in the process of the project implementation.

\section{Existing Problems and Solutions}

\subsection{The Behavior of Learned Helplessness}

Learned helplessness refers to a state of mind and behavior that one is incompetent when facing problems after he or she meets with failure and frustration. "Learning helplessness" was proposed by American psychologist Seligman (M.E.P.) in his study of animals in 1967. Psychologists later proved that this phenomenon also occurs in humans. If one perceives that his or her behavior is unlikely to achieve a specific goal, or has no possibility of success, he or she may give away to a state of incompetence or self-defeating. Specifically, one may show cognitive deficits, decrease of motivation, and maladjustment of emotion, etc. During the course of implementation of the project-based assignment, some students have a negative attitude towards learning and are not 
interested in such assignment. No matter how the teachers and other students in the same group persuade them to do any assignment, they are unwilling to participate and refuse to cooperate. As a result, his or her name appear on the exercise book, but actually he or she has done nothing. It is a typical behavior of learned helplessness. In response to this phenomenon, teachers should:

- Positively evaluate students and strngthen their self-control beliefs in the process of project implementation. When evaluating their academic performance, teachers should treat them objectively, and provide them with concerns, encouragement and help, pay attention to their progress, and make timely feedback on their positive behavior, persistent efforts and performance in the learning process so that they may form a good self-control belief, improve self-confidence, and face failure objectively and bravely.

- Instruct the students to make correct attribution and guide them to have efficient training.

Those who have the behavior of learned helplessness often have attributional barriers. If teachers can provide them with some effective training, they may overcome attribution difficulties and find positive attribution methods. To this end, teachers should try to create certain situations in which students may learn and experience success or failure. Meanwhile, teachers may also introduce some successful stories in learning activities timely, and ask students to discuss and analyze the reasons for success or failure. In this case, those who have the behavior of learned helplessness may change their way of incorrect attribution after patient attribution training. At the same time, teachers should strive to improve students' cognitive strategies and improve their ability to solve practical problems. In the translation training, students are encouraged to make every effort to improve their self-esteem and self-confidence.

- Create a friendly environment and a harmonious relationship between teachers and students. Teachers should actively create a harmonious learning atmosphere, a sincere and equal relationship between teachers and students, help each other, develop and cultivate students' different interests, meet their multi-level needs, and enhance their self-confidence in learning activities.

- Guarantee the continuity of love and recognize the differences between the students and their development at different levels. Due to the bad habits of some students, it may lead to weaken their intellectual quality and the formation of learned helplessness. In view of this, teachers should help these students establish correct learning concepts, and let them know that their original ability can be promoted only by learning. In addition, teachers should patiently encourage them to get rid of bad learning habits to avoid forming learned helplessness.

\subsection{Falsified Behavior}

Since the marks of the project-based assigment are part of their the final total score ( accounting for $30 \%$ of the total score), every student has to do it to get the corresponding score. However, some students have insufficient understanding of the implementation of the project, and the purpose of doing the homework is not to improve their translating competence but to get marks. Therefore, in the process of implementation of the project, they don't seriously think it over, even worse, they are unwilling to experience the translation process themslves, instead, they often download some versions fragmentarily online to make it up. As the result, the quality of their transltion works is poor without any logic. In response to this phenomenon, teachers should strengthen the guidance and help students establish a correct view of learning. Chairman Mao once said: "If you want to know the taste of a pear, you have to taste it yourself." Translation is a practical activity. Students who want to master translation methods and techniques and improve their translation skills must practice a lot. At the same time, the evaluation mechanism should be adjusted, and students who do not participate in the practice will not get any marks.

\subsection{Procrastinating Behavior}

Nowadays a large number of college students are lazy in hands-on, especially for complex and comprehensive translation, they often perform in a "procrastination" way. Project-based assignment is a relatively complicated and comprehensive task. Just like a prospectus, it must be planned completely as a whole. Firstly, the students should understand and write out the purpose and 
significance of the project implementation. Secondly, they should presuppose the key issues to be solved in the project.Thirdly, in order to solve the problems, they are required to read a large amount of relevant literature (students often think that it is a waste of time, they do not intend to do any reading) to get the solutions to the problems, and they are also required to write a summary of the whole practice process which really tests their comprehensive ability and the willpower.

Through the practice of students of three different grades, a considerable number of students have procrastinating behavior, either "scraping or cutting materials", or coping answers from network or other students. What is more serious is that, when the time for handing over their works, the excuses are often used to delay the processing time. After the teacher has urged for several times, they hurriedly complete the assignment and reluctantly hand them in. As the result, the assigment they hand in is either incomplete in contents, or deviating from the theme, or logically confusing. In this case, its original purpose of implementing the project-based assigment is nothing. In response to this phenomenon, teachers should strengthen students' sense of responsibility and self-discipline. The reason why some students are "procrastination" is serious, the key is that their learning goals are not clear and the sense of responsibility is weak. Therefore, in the process of teaching, the teacher should continuously strengthen their sense of responsibility, the teacher should guide and help them to make the necessary plans to overcome the "procrastination", and supervise them to strengthen self-discipline and take action according to their own plans.

\section{Conclusion}

In college English translation teaching, not only the teachers' teaching philosophy, knowledge level, professional quality, control ability, teaching wisdom, teaching methods, but also the students'knowledge base, ability levels, study habits, and learning methods, etc. are involved in. ${ }^{[6]}$ Under the guidance of constructivism theory, proper implementation of project-based assignment in English translation teaching can not only change the educational philosophy of teachers, but also enable each student to possitively participate in the whole translation process. It turns out that students' knowledge structures are constructed by themselves and their critical thinking ability and innovation ability are improved as well. Meanwhile, their teamwork spirit is strengthened through cooperation, which lays a solid foundation for their future development.

\section{Acknowledgement}

Fund Project: This is one of the achievements of 2016 Shandong Provincial Undergraduate University Teaching Reform Research Project - Research on Teaching Reform of English-Chinese Translation Practice under the Framework of 'Partitioning Classroom + Project-based Assignment' (Project No.: Z2016M070), and 2017 School-level Project-A Study of English Translation Teaching and the Development of Critical Thinking in the Era of "Internet +". (Project No.: 2017JY08).

\section{References}

[1] Hu Chengwei. On the Application of Constructivism Learning Theory in College English Teaching [J].Journal of Hubei University of Economics (Humanities and Social Sciences), 2012, (1):205

[2] Chen Yue. A Review of Constructivism and Constructivism Learning Theory. Only Existing Education - Rational Thinking. www.being.org.cn

[3] Ministry of Education of the People's Republic of China. National English Curriculum Standards (Experimental Draft). Beijing Normal University Press, 2001

[4] Liu Heping. On the Principles and Methods of Undergraduate Translation Teaching [J]. Chinese Translation, 2009 (6): 45-46. 
[5]Wang Xiaomin. Research on Constructivism Teaching Theory in Translation Teaching Application [J]. English Teaching, 2009, (6): 115

[6]Wang Ying. Reform of College English Translation Teaching Model under the Guidance of Constructivism Theory [J]. Journal of Liaoning Medical College, Social Sciences Edition, 2016, (2) (Vol. 14, No. 1): 138-140

Sunmin (1964-), female, associate professor, from Weifang, Shandong province, is a teacher who graduated from Westminster University, and obtained MA. Degree.

The main study field: Bylingual Translation and Chinese and Western Culture.

Tel:15154416168, e-mail:2674597727@qq.com

Qiu Yanchun(1977-), female, associate professor, from Gaomi, Shandong province, is a teacher who graduated from Hunan University, and obtained MA. Degree.

The main study field: Applied Linguistics, Translation Teaching

Tel: 15265207568, e-mail:975581248@qq.com 